\title{
FIN DE ETAPA
}

Queridos amigos:

Desde que en 1996 sugerí a las profesoras y profesores del Departamento de Derecho Político de la UNED que impulsásemos una nueva revista sobre nuestra disciplina, sin ánimo de competir con las existentes y con el único propósito de ofrecer una visión dialéctica del constitucionalismo de nuestra época, ha transcurrido un cuarto de siglo. Y quien os escribe estas breves páginas de despedida ha cumplido 78 años y está en el deber de pensar en entregar el testigo de la dirección de la misma y de procurar terminar un libro, en largo proceso in fieri, que demanda mayores esfuerzos para que pueda ver la luz.

Las revistas científicas acostumbran a tener un largo recorrido, en el que se suceden unas etapas a otras y Teoría y Realidad Constitucional no tiene porqué constituir una excepción. Como suele ser general en las publicaciones científicas, la nuestra ha acogido trabajos de los mejores profesores de Derecho Constitucional, que en sus páginas unas veces exponían tesis y otras planteaban cuestiones, pero siempre transmitían su pasión por el estudio de materias del ordenamiento constitucional, especialmente complejas. Se trata de un afán que nos realiza a quienes vivimos la discreta vocación hacia el estudio, con la aspiración de contribuir en alguna pequeña medida, a la progresiva mejora del Estado Democrático de Derecho, de sus instituciones y de sus prácticas. Esta pasión tiene algo de vicio y como tal puede conllevar la positiva secuela de su contagio al profesorado más joven.

A la dirección de una pequeña revista como la nuestra le corresponde sugerir temas que demande la realidad, o que deban ser objeto de polémica constructiva, sobre los que pedir colaboraciones, lo que requiere reflexión conjunta con los miembros del equipo de redacción, procurar elegir con objetividad el autor o autores que nos pueden hacer interesantes aportaciones. Y, al tiempo permanecer abiertos a acoger opiniones discrepantes o complementarias. En nuestro primer número, bajo el título: Razón de ser ya apunté mi modesto propósito de que esta fuera una publicación en que tuviese cabida una visión dinámica y aún dialéctica del constitucionalismo de nuestra época, para arrojar luz sobre materias que o bien se encuentran cuestionadas, o bien nos parecen propias de controversia. Deseábamos abrir una senda al debate e incluso a la polémica, según decíamos: 
«nunca hiriente y mantenida por supuesto, en los términos que son propios del mundo universitario, que no puede desconocer sus raíces en las escuelas peripatéticas griegas». Era toda una invitación al diálogo a los amigos para avanzar de la mano, paso a paso, por el camino del estudio y de la investigación. En ocasiones para arrojar luz sobre cuanto necesite de replanteamientos y, en su caso, de reformas de nuestra Constitución, muchas fácilmente hacederas por la vía del artículo 167 de nuestra Carta Magna, pero en la práctica dificilísimas — salvo que se nos exija desde las alturas de la Unión Europea- por la alergia de nuestra clase política a debates de altura, constructivos y sosegados que puedan desembocar en una reforma constitucional.

Esta publicación quizá ha dedicado poca atención a nuestro constitucionalismo histórico, aunque puse mucho interés en rescatar las semblanzas de quienes han sido maestros de nuestra disciplina a lo largo de los siglos XIX y Xx. No ignoramos la importancia de nuestra trayectoria histórica, pero - dado lo limitado del espacio disponible - decidimos dar prioridad a las reflexiones sobre la problemática constitucional del complejo presente, que incluye el difícil proceso de federalización progresiva de la Unión Europea, que cada vez exige más que los constitucionalistas completemos la visión de los internacionalistas. Centrar la atención de nuestros jóvenes profesores en hacer avanzar este gran proyecto histórico nos ha parecido, más que conveniente, una necesidad imperiosa. Hemos sido conscientes de que en este terreno pedíamos colaboraciones sobre lo que no teníamos claro. Pues dada la impronta que de joven me dejó la lectura de Ortega y Gasset, estimo capital saber lo que no se sabe. Y creo que llevaba razón Henry Parker al decir «Cuanto más se sabe, más se duda», pero a la par es cierto que las dudas se superan mediante la reflexión profunda, el estudio y el debate con quien comparte preocupaciones, aunque con enfoques diversos.

Creo que entre todos hemos logrado que Teoría y Realidad Constitucional sea una prueba de que los profesores de Derecho Constitucional no solo predicamos que el artículo 1 de nuestra Constitución propugna como valor superior de su ordenamiento jurídico el pluralismo político, sino que creemos en su imprescindibilidad para que nuestro Estado sea genuinamente democrático.

Estas páginas siempre han estado abiertas al ancho abanico de visiones de altura sobre las materias que debíamos abordar, dando prioridad a la conexión Derecho Constitucional y realidad socio-política, reduciendo en lo posible las comprensibles tentaciones hacia la evasión pura y simple, en beneficio del realismo científico en nuestra disciplina. No es casual que para cerrar mi modesta etapa como director de la revista haya elegido el presente número monográfico sobre el sistema electoral, pues además de su interés intrínseco, creo que ha de conllevar la compleja traslación del pluralismo político de una sociedad a sus instituciones representativas y facilitar que los electores puedan optar por los mejores. Sabido es que todos, lejos de estar en posesión de la verdad, disfrutamos de visiones parciales que debemos complementar con las de los otros, que son parte de los nuestros. Lo que se puede lograr mediante un debate lúcido a la debida altura y 
protagonizado por quienes conocen la materia objeto del mismo y están en condiciones de argumentar constructivamente. Ese es quizás el fin principal a que debe tender un buen sistema electoral y en ello hay un cierto paralelismo con el objetivo académico fundacional de esta publicación, que confiamos que sea objeto de amejoramiento paulatino en la nueva etapa.

Tras dejar la dirección de Teoría y Realidad Constitucional en manos más jóvenes, confío en que siga siendo útil para el avance de nuestra ciencia jurídico constitucional y para la formación de nuestro profesorado joven, con el que tenemos contraído el deber ético de trasladarle nuestros pocos conocimientos y nuestro vicio de procurar siempre saber algo más a fin de que nos superen.

Debo dejar constancia de que esta revista ha alcanzado su nivel actual, no gracias a este director que se despide, sino fundamentalmente a todos y cada uno de los integrantes de nuestro equipo — que ha operado durante años con gran entendimiento y sin fricciones - y a cuantos buenos amigos de nuestra asignatura nos han ofrecido sus artículos, notas y especialmente su óptima disposición a cooperar en la tarea. Estas palabras no son de cortesía, sino de sincero reconocimiento de que la paternidad de Teoría y Realidad Constitucional es colegiada, pues abarca a cuantos han cooperado desinteresadamente aportando contribuciones del mayor interés. El alto nivel que ha alcanzado la revista se debe tan solo a sus colaboradores. Teoría y Realidad Constitucional, la han hecho los autores de estudios, notas y otras secciones; con ellos, con el equipo de redacción, y con los lectores he contraído una deuda impagable.

Por supuesto, este viejo director tras dejar paso a los más jóvenes, continuará disponible para dialogar y aportar puntualmente lo que, en pequeña medida, esté a su alcance, pues un profesor vocacional nunca puede dimitir de su vocación, ni dejar de ser incondicional amigo de sus buenos amigos.

Un gran abrazo para todos, 
